\title{
Endonasal endoscopic transsphenoidal chiasmapexy using a clival cranial base cranioplasty for visual loss from massive empty sella following macroprolactinoma treatment with bromocriptine: case report
}

\author{
G. Rene Alvarez Berastegui, MD, ${ }^{1}$ Shaan M. Raza, MD, ${ }^{1}$ Vijay K. Anand, MD, ${ }^{2}$ and \\ Theodore H. Schwartz, MD1,2,3
}

\begin{abstract}
Departments of ${ }^{1}$ Neurosurgery, ${ }^{2}$ Otolaryngology, and ${ }^{3}$ Neuroscience, Weill Cornell Medical College, NewYork-Presbyterian Hospital, New York, New York
\end{abstract}

\begin{abstract}
Visual deterioration after dopamine-agonist treatment of prolactinomas associated with empty sella syndrome and secondary optic apparatus traction is a rare event. Chiasmapexy has been described as a viable treatment option, although few cases exist in the literature. Here, a novel endonasal endoscopic approach to chiasmapexy is described and its efficacy is demonstrated in a case report.

A 55-year-old female patient with a history of a giant prolactinoma and 14 years of treatment using dopaminergic agonist therapy presented to our institution with a 1-month history of visual changes. Neuroophthalmological examination confirmed severe bitemporal field defects, and MRI revealed a large empty sella with downward optic chiasmal herniation. Endoscopic endonasal chiasmapexy was performed by elevating the chiasm with lumbar drainage and filling the clival and sellar defect with an extradural liquid (HydroSet; a cranioplasty bone cement), and a piece of AlloDerm was used to cover and cushion the chiasm. Postoperative imaging demonstrated successful anatomical elevation of the optic apparatus, and the patient showed functional improvement in the visual field at 3 months postoperatively.

Although rare, massive empty sellar and chiasmal descent from macroadenoma treatment can result in progressive visual loss. Here, a novel technique of endonasal endoscopic extradural cranioplasty aided by lumbar drainage is reported, which appears to be an effective technique for stabilizing and possibly reversing anatomical and visual deterioration.

http://thejns.org/doi/abs/10.3171/2015.2.JNS142015
\end{abstract}

KEY WORDS bromocriptine; empty sella; endonasal; endoscopic; plasty; prolactinoma; transsphenoidal; chiasmapexy; pituitary surgery

$\mathrm{T}$ HE term "empty sella turcica" was first coined by Busch in $1951^{2}$ after examining 788 sellae of patients with no known pituitary disease. Colby and Kearns in $1962^{5}$ and then Lee and Adams in $1968^{16}$ described the term "empty sella syndrome" for patients with pituitary tumors who received treatment-either resection, radiation therapy, or both - and, at some time, subsequently presented with deterioration of their visual function that was suggestive of tumor recurrence, but no tumor was found when the sella was explored surgically. Currently, 2 types of empty sella syndrome are described in the literature: primary and secondary. The former was described initially by Kaufman in $1968^{13}$ as a "distinct anatomical and radiographic entity" in patients with incompletely closed or wide-ring diaphragma sellae with the pituitary gland flattened to the bottom who presented with visual or endocrinological disturbances or spontaneous CSF rhinorrhea. Secondary empty sella syndrome refers to the same constellation of symptoms, but in patients who have been treated for sella turcica tumors. After the completion of medical, surgical, or radiation therapy, the imaging of this category of patients shows the descent of the optic nerves, chiasm, or even the posteromedial part of the frontal lobes into the tumor bed or "empty sella." 
The first reported case of visual decline while on dopamine-agonist therapy for a prolactinoma was a 35-year-old male patient whose medical therapy failed and was taken for transsphenoidal surgery that resulted in a dense postoperative bitemporal hemianopsia. ${ }^{18}$ Welch in $1971^{25}$ first described the term "chiasmapexy" as a transcranial technique for untethering the optic nerve and anterior cerebral artery that were depressed into the sella by incising the diaphragma and inserting small pieces of silicone sponge beneath the optic nerve until it was restored to a more normal position. Seven months after the operation, preoperative visual loss was restored to normal.

There are only 3 reported cases of chiasmapexy for bromocriptine-treated macroprolactinoma, 2 of which were done through a craniotomy. The goals of chiasmapexy are either lysis of the adhesions between the optic chiasm and dura or elevation of the dura itself. The former requires a craniotomy, and the latter can be done through an extradural minimally invasive endonasal endoscopic approach. In this paper, we describe the latter technique, which utilizes a novel clival cranial base cranioplasty process, and discuss its advantages over previously reported techniques.

\section{Case Report}

\section{History and Examination}

A right-handed 55-year-old female patient with a history of a prolactinoma presented to our institution with a several-year history of visual deterioration, which had worsened over the past month and described as tunnel vision without issues of visual acuity or color perception. Her treatment history was notable for including the prior management of a giant macroprolactinoma diagnosed 14 years earlier that was treated with $5 \mathrm{mg}$ of bromocriptine daily, resulting in massive shrinkage in the tumor. Her computerized visual fields showed a bitemporal hemianopsia (Fig. 1). Her preoperative prolactin levels were $10.2 \mathrm{ng} / \mathrm{ml}$ and had been stable for years and within the normal range. Her pretreatment MRI study was not available, but she was found to have a large empty sella with downward herniation of the optic chiasm and the floor of the third ventricle (Fig. 2A-C). The distance between the vein of Galen-straight sinus confluence and the anterior communicating artery (ACoA) was $7.2 \mathrm{~cm}$ (Fig. 2C). Preoperative CT angiography (CTA) showed that the entire clivus had been eroded by the tumor, which was not gone, leaving minimal bone with which to buttress any sort of chiasmapexy graft (Fig. 2A).

\section{Operative Plan}

The decision was made to perform an extradural elevation of the chiasm through an endonasal endoscopic approach and to rebuild the clivus using HydroSet liquid bone cement cranioplasty to facilitate chiasmal elevation. To avoid pushing on the chiasm, the chiasm and dura would be elevated with intraoperative lumbar drainage of the CSF.

\section{Operative Technique}

After anesthesia induction, a lumbar drain was placed which softened the encephalocele and aided in its reduction. We administered $0.25 \mathrm{ml}$ of $10 \%$ fluorescein (AKFluor, AKORN) with $10 \mathrm{ml}$ of CSF via the lumbar drain to assist in the intraoperative identification of CSF leaks. ${ }^{20,23}$ Once in rigid head fixation, the patient was registered with frameless stereotactic equipment to preoperatively perform CTA with contrast. Under endoscopic visualization using a $0^{\circ}, 18-\mathrm{cm}$-long, 4-mm-diameter rigid endoscope (Karl Storz), the middle and superior turbinates were gently lateralized to expose the natural ostium of the sphenoid sinus. A nasoseptal flap was harvested for skull base closure at the end of the procedure in case of CSF leakage. The sphenoid sinus and posterior ethmoid air cells were opened widely. Upon entry into the sphenoid, the encephalocele was readily visualized. Careful extradural dissection was performed to expose the entire encephalocele from the planum down to the floor of the clivus (Fig. 3A). The lumbar drain was opened, and $40 \mathrm{ml}$ was removed with gentle pressure on the dura and meningocele using a cottonoid patty to elevate the chiasm. Once the encephalocele was adequately reduced, AlloDerm (LifeCell Corp.)
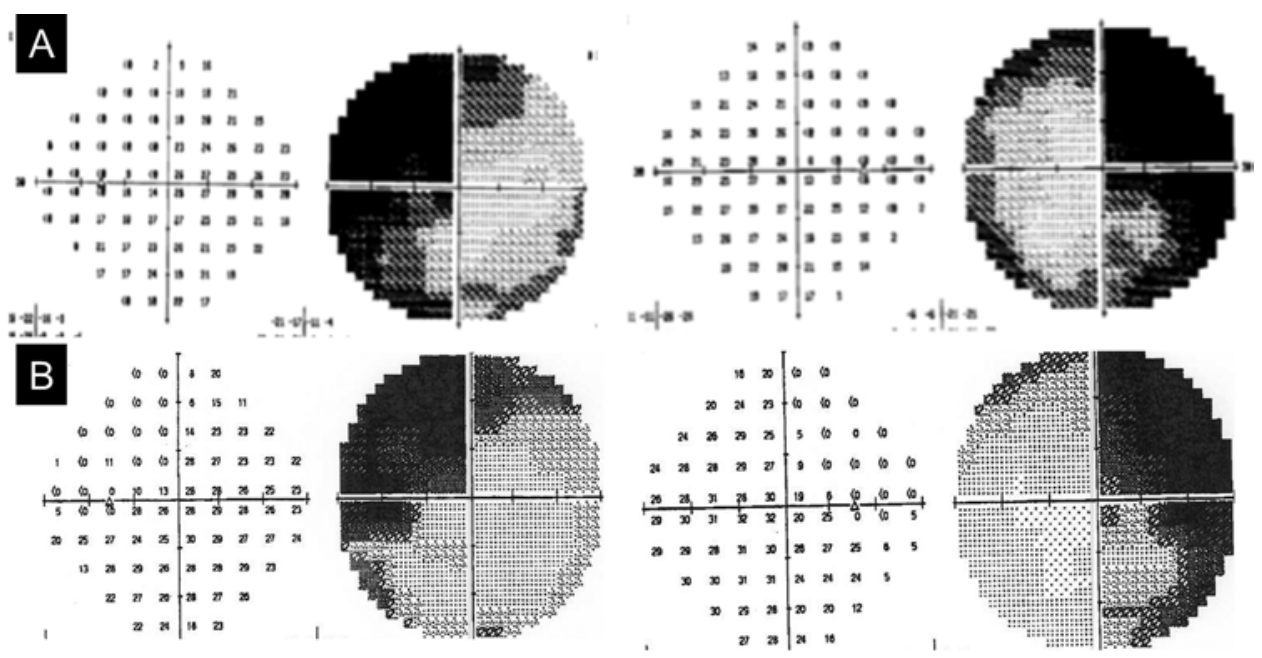

FIG. 1. A: Preoperative visual fields showing bitemporal hemianopsia. B: Postoperative visual fields showing improvement in the nasal and inferior temporal fields and stability in the superior temporal fields. 

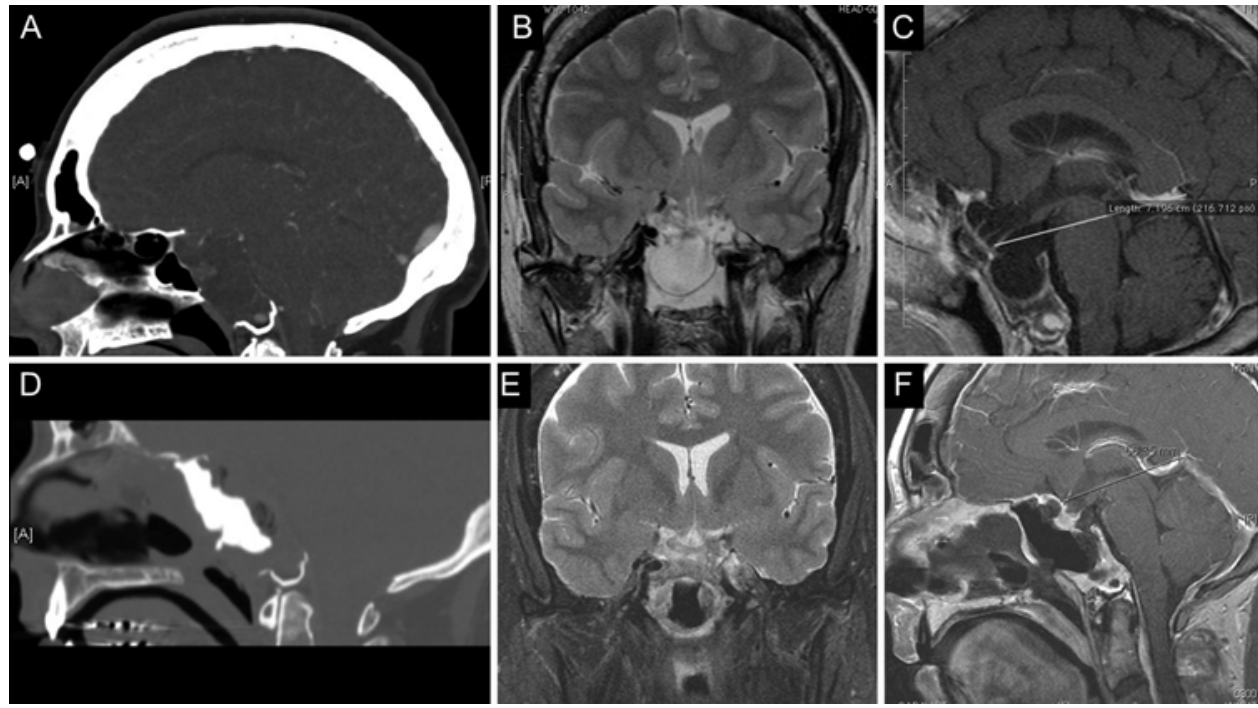

FIG. 2. A-C: Preoperative images. Sagittal CT angiogram (A), coronal T2-weighted MR image (B), and sagittal T1-weighted MR image with contrast $(C)$ showing an arachnoid encephalocele occupying an enlarged empty sella with descent of the optic nerves and ACOA. D-F: Postoperative images. Sagittal CT angiogram (D) showing the skull base cranioplasty. Coronal T2-weighted MR image (E) and sagittal T1-weighted MR image with contrast $(F)$ showing the corrected skull base defect and the return of the chiasm to a better position.

was placed in the epidural space to buttress the dural sac. This was then supported by a rigid construct consisting of the HydroSet injectable bone substitute (Stryker Leibinger $\mathrm{GmbH} \& \mathrm{Co} . \mathrm{KG})$ that was placed into the clival defect and sphenoid sinus (Fig. 3B and C). The plasty material hardened quickly and was immobile. This was covered with a vascularized nasoseptal flap followed by a final layer of DuraSeal (Covidien) to keep the flap in place (Fig. 3D). Floseal (Baxter) was then placed in the sphenoid and ethmoid sinuses for hemostasis, followed by Telfa nasal splints that were removed on postoperative Day 1, which served to decrease nasal discharge overnight. The lumbar
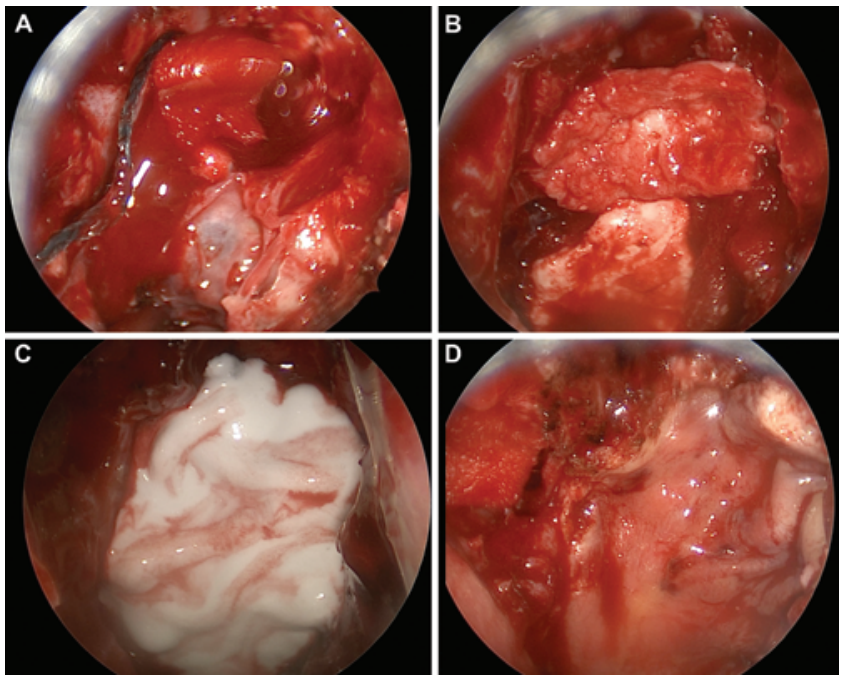

FIG. 3. Intraoperative findings. A: Exposition of sellar and clival arachnoid encephalocele. B: AlloDerm was placed over the optic chiasm. C: Sella packing with HydroSet (injectable bone substitute). D: Vascularized nasoseptal flap covering the corrected skull base defect, which is covering the HydroSet, with vascularized mucosa. drain was left open for 24 hours at $5 \mathrm{ml} /$ hour and then removed the night after surgery.

\section{Visual and Radiological Outcomes}

The patient had a good postoperative recovery and went home after 3 days. Eight months later at the evaluation at the clinic, she reported subjective improvement in her visual function. The computerized visual fields showed improvement of the nasal and inferior temporal fields and stability in the superior temporal fields (Fig. 1B). Her last brain MRI study revealed an adequate elevation of the sellar contents, including the optic nerves, and the ACoA to a normal position. The distance between the vein of Galenstraight sinus confluence and ACoA moved from $7.2 \mathrm{~cm}$ preoperatively to $5.6 \mathrm{~cm}$ postoperatively, showing a 1.6$\mathrm{cm}$ elevation of the optic chiasm (Fig. 2C and F).

\section{Discussion}

Since Moster's ${ }^{18}$ first description in 1985 of delayed visual loss after dopamine agonist treatment for prolactinoma, 17 cases have been described (Table 1). Of these, only 3 were treated with surgical management. In the remaining patients, the dose of the dopamine agonist was either decreased or completely discontinued, resulting in variable improvement in vision in some patients and several instances of tumor regrowth. ${ }^{8,21}$ Four years after Moster's paper, Kaufman et al. ${ }^{14}$ specifically referred to chiasmapexy as a therapeutic option.

The etiology of delayed visual deterioration following bromocriptine therapy for empty sella syndrome has not been elucidated. Chiasmal herniation into a secondary empty sella in association with perineural scar tissue has been hypothesized to compromise chiasmal perfusion, but many reports show normal visual status in patients with intrasellar encephaloceles; therefore, no clear correlation 


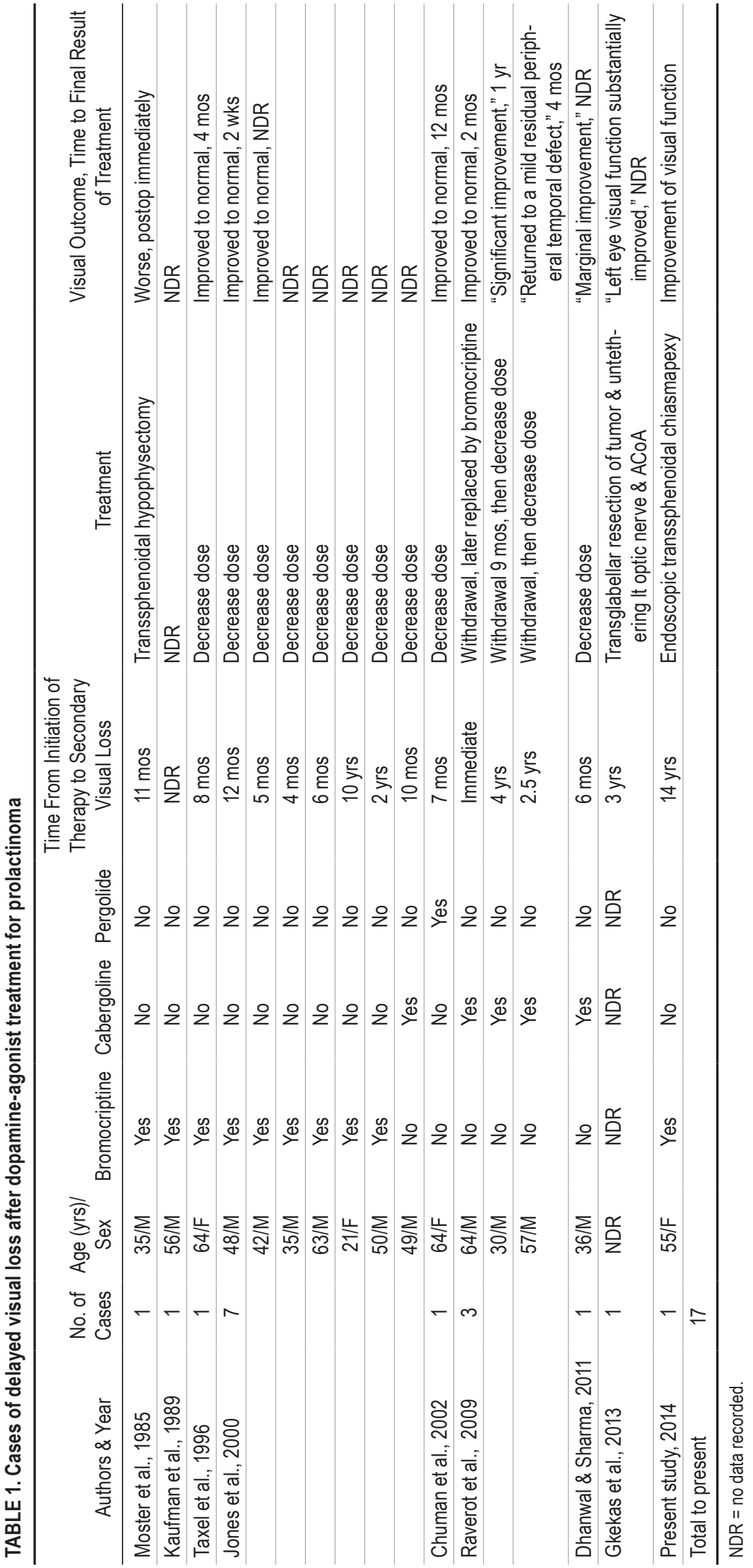




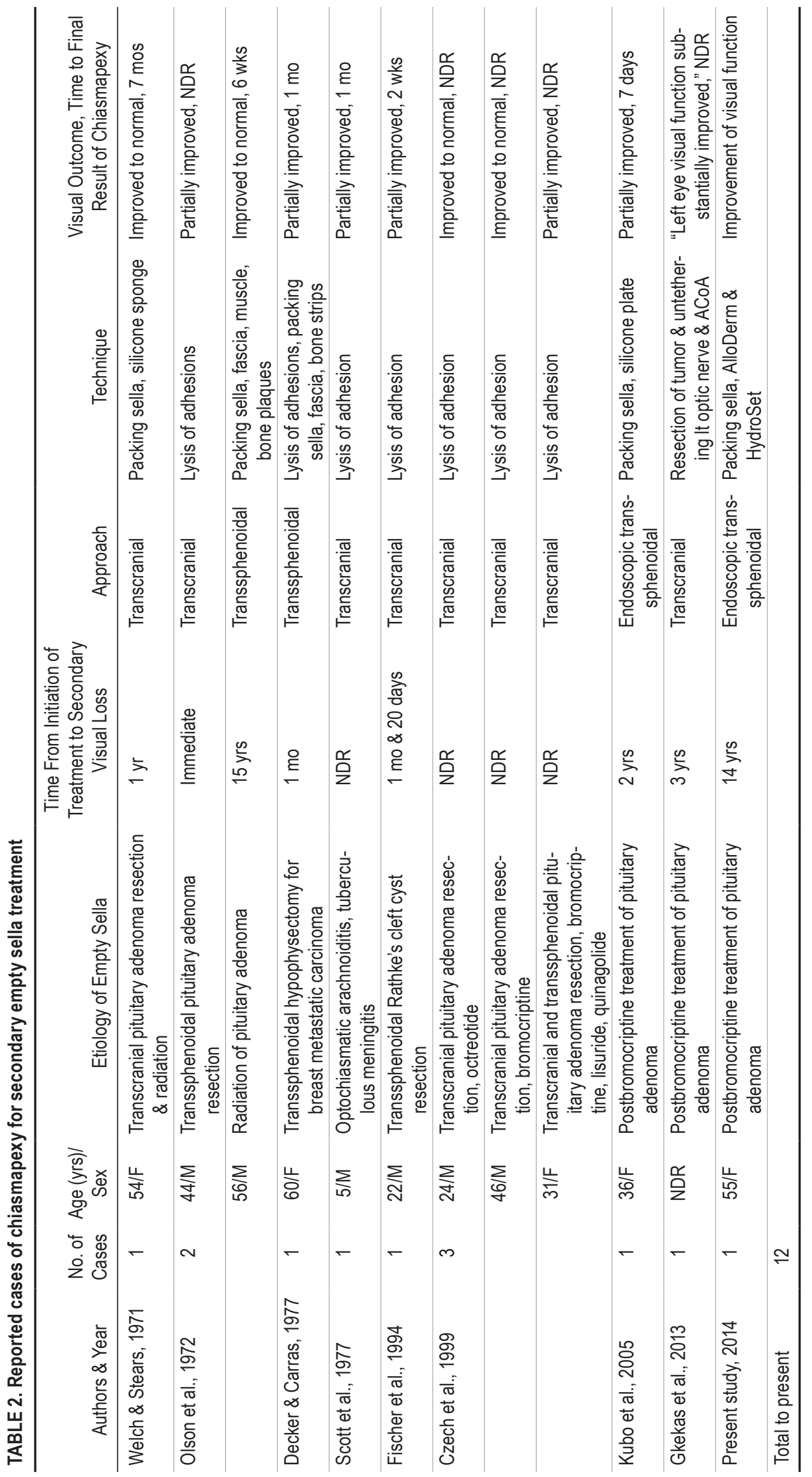


has been identified between chiasmal intrasellar prolapse and visual impairment. . $21,24^{2}$ Other proposed hypotheses include the possibility that the dopaminergic agonist causes direct toxicity, vasospasm-induced ischemia, or reversible perivascular fibrosis. ${ }^{4,12,21,24}$

Until now there have been 11 cases of chiasmapexy for secondary empty sella reported in the literature and only 3 cases of postdopaminergic therapy for prolactinomas (Table 2). Of these, 2 cases had been treated transsphenoidally using a microscope and 1 with an endoscope (Table 2). The use of a cranioplasty material to reconstruct the clival defect has never been reported until this current case. In 1985, Moster reported a case of transsphenoidal hypophysectomy with poor postoperative visual outcome, which was possibly due to worsening empty sella and thus chiasm traction. Twenty years later, Kubo et al. ${ }^{15}$ described performing endoscopic transsphenoidal chiasmapexy in 2 patients, one with primary empty sella and the other with secondary empty sella caused by bromocriptine for the treatment of prolactinoma; visual function recovered in both patients. Finally, Gkekas et al. ${ }^{10}$ described a transglabellar approach in which "left eye visual function substantially improved."

Chiasmapexy techniques are based on 2 principles: chiasm unthetering ${ }^{9}$ and elevation of the sellar contents. ${ }^{11,19}$ The former, which requires lysis of the adhesions, requires a craniotomy and intradural exposure. The latter, on the other hand, can be done extradurally with sellar packing. The approach can be either transcranial or transsphenoidal, which must be decided based on the etiology of the chiasmal descent; however, the endonasal endoscopic approach offers many advantages, and the use of bone cement plasty is also theoretically advantageous.,17 With regard to the need to lyse adhesions to elevate the chiasm, this can only really be done transcranially since the chiasm may adhere to the basal dura to which it is tethered. Rather than risk devascularizing the chiasm, it is more logical to elevate the dura along with the chiasm into a normal position in order to release the traction on the chiasm. This can be done through an extradural transsphenoidal approach, which reduces the risk of CSF leakage as well as the risk of ischemia to the chiasm.

With regard to the material used to elevate the chiasm, several options exist. The muscle and fascia are autologous, nonvascularized materials which can be reabsorbed, and thus the chiasm elevation would only be temporary. Moreover, in some cases, delayed necrosis and adhesion formation have been reported. Bone and cartilage are good choices because they are rigid and not as susceptible to reabsorption, but these are not always available and difficult to conform into exactly the correct size and shape. Since 1971, synthetic materials such as silicone sponge, ${ }^{25}$ silicone plates, ${ }^{15}$ and silastic coils ${ }^{26}$ have been described that are softer and more malleable. However, these materials require a buttress on which to rest, such as a residual clivus or other rigid component of the skull base. In our case, there was so much eroded bone that the clivus needed to be rebuilt, and we essentially tried to fill the clival defect with bone cement to make sure that it held up the encephalocele adequately and was in contact with the residual bone of the clivus. Depending on the amount of erosion of the bone, the amount of cement will differ between patients. Finally, we placed a soft layer of AlloDerm between the chiasm and the plasty material to soften the pressure on the chiasm, buffer intracranial pulsations, and prevent any exothermic reaction of the plasty material from creating a thermal injury to the chiasm. The results speak for the efficacy of the technique.

Although rare, visual apparatus herniation into an empty sella can cause visual deterioration that is sometimes associated with the medical therapy for macroprolactinomas. Here, we have described a new extradural minimally invasive approach that uses endonasal endoscopic clival cranial base plasty, AlloDerm, and lumbar drainage.

\section{References}

1. Bangash MH, Clarke DB, Holness RO: Brain \& chiasmal herniations into sella after medical treatment of prolactinoma. Can J Neurol Sci 33:240-242, 2006

2. Busch W: Die Morphologie der Sella turcica und ihre Beziehungen zur Hypophyse. Virchows Arch 320:437-458, 1951

3. Cappabianca P, Cavallo LM, de Divitiis E: Endoscopic endonasal transsphenoidal surgery. Neurosurgery 55:933-941, 2004

4. Chuman H, Cornblath WT, Trobe JD, Gebarski SS: Delayed visual loss following pergolide treatment of a prolactinoma. $\mathbf{J}$ Neuroophthalmol 22:102-106, 2002

5. Colby MY Jr, Kearns TP: Radiation therapy of pituitary adenomas with associated visual impairment. Proc Staff Meet Mayo Clin 37:15-24, 1962

6. Czech T, Wolfsberger S, Reitner A, Görzer H: Delayed visual deterioration after surgery for pituitary adenoma. Acta Neurochir (Wien) 141:45-51, 1999

7. Decker RE, Carras R: Transsphenoidal chiasmapexy for correction of posthypophysectomy traction syndrome of optic chiasm. Case report. J Neurosurg 46:527-529, 1977

8. Dhanwal DK, Sharma AK: Brain and optic chiasmal herniations into sella after cabergoline therapy of giant prolactinoma. Pituitary 14:384-387, 2011

9. Fischer EG, DeGirolami U, Suojanen JN: Reversible visual deficit following debulking of a Rathke's cleft cyst: a tethered chiasm? J Neurosurg 81:459-462, 1994

10. Gkekas N, Primikiris P, Georgakoulias N: Untethering of herniated left optic nerve after dopamine agonist treatment for giant prolactinoma. Acta Neurochir (Wien) 155:495496, 2013

11. Guinto G, del Valle R, Nishimura E, Mercado M, Nettel B, Salazar F: Primary empty sella syndrome: the role of visual system herniation. Surg Neurol 58:42-48, 2002

12. Jones SE, James RA, Hall K, Kendall-Taylor P: Optic chiasmal herniation - an under recognized complication of dopamine agonist therapy for macroprolactinoma. Clin Endocrinol (Oxf) 53:529-534, 2000

13. Kaufman B: The "empty" sella turcica-a manifestation of the intrasellar subarachnoid space. Radiology 90:931-941, 1968

14. Kaufman B, Tomsak RL, Kaufman BA, Arafah BU, Bellon EM, Selman WR, et al: Herniation of the suprasellar visual system and third ventricle into empty sellae: morphologic and clinical considerations. AJR Am J Roentgenol 152:597608, 1989

15. Kubo S, Hasegawa H, Inui T, Tominaga S, Yoshimine T: Endonasal endoscopic transsphenoidal chiasmapexy with silicone plates for empty sella syndrome: technical note. Neurol Med Chir (Tokyo) 45:428-432, 2005

16. Lee WM, Adams JE: The empty sella syndrome. J Neurosurg 28:351-356, 1968

17. Leng LZ, Anand VK, Schwartz TH: Endoscopic transsphe- 
noidal approach to the sella, in Schwartz TH, Anand VK (eds): Endoscopic Pituitary Surgery. New York: Thieme, 2012, 146-160

18. Moster ML, Savino PJ, Schatz NJ, Snyder PJ, Sergott RC, Bosley TM: Visual function in prolactinoma patients treated with bromocriptine. Ophthalmology 92:1332-1341, 1985

19. Olson DR, Guiot G, Derome P: The symptomatic empty sella. Prevention and correction via the transsphenoidal approach. J Neurosurg 37:533-537, 1972

20. Placantonakis DG, Tabaee A, Anand VK, Hiltzik D, Schwartz TH: Safety of low-dose intrathecal fluorescein in endoscopic cranial base surgery. Neurosurgery 61 (3 Suppl):161-166, 2007

21. Raverot G, Jacob M, Jouanneau E, Delemer B, Vighetto A, Pugeat M, et al: Secondary deterioration of visual field during cabergoline treatment for macroprolactinoma. Clin Endocrinol (Oxf) 70:588-592, 2009

22. Scott RM, Sonntag VK, Wilcox LM, Adelman LS, Rockel TH: Visual loss from optochiasmatic arachnoiditis after tuberculous meningitis. Case report. J Neurosurg 46:524-526, 1977

23. Tabaee A, Placantonakis DG, Schwartz TH, Anand VK: Intrathecal fluorescein in endoscopic skull base surgery. Otolaryngol Head Neck Surg 137:316-320, 2007

24. Taxel P, Waitzman DM, Harrington JF Jr, Fagan RH, Rothfield NF, Chen HH, et al: Chiasmal herniation as a complication of bromocriptine therapy. J Neuroophthalmol 16:252257, 1996
25. Welch K, Stears JC: Chiasmapexy for the correction of traction on the optic nerves and chiasm associated with their descent into an empty sella turcica. Case report. J Neurosurg 35:760-764, 1971

26. Zona G, Testa V, Sbaffi PF, Spaziante R: Transsphenoidal treatment of empty sella by means of a silastic coil: technical note. Neurosurgery 51:1299-1303, 2002

\section{Disclosure}

Dr. Schwartz is a consultant for Karl Storz, owns stock in Vision Sense, and received clinical or research support for the study described from the National Institutes of Health.

\section{Author Contributions}

Conception and design: all authors. Acquisition of data: all authors. Analysis and interpretation of data: all authors. Drafting the article: all authors. Approved the final version of the manuscript on behalf of all authors: Schwartz. Administrative/techni$\mathrm{cal} /$ material support: Schwartz. Study supervision: Anand.

\section{Correspondence}

Theodore H. Schwartz, Department of Neurological Surgery, NewYork-Presbyterian Hospital, Weill Medical College of Cornell University, 525 East 68th St., Box \#99, New York, NY 10065. email: schwarh@med.cornell.edu. 